\title{
EDUCACIÓN FEMENINA EN LA EDAD MODERNA: CONSTITUCIONES DEL COLEGIO DE DONCELLAS NOBLES DE NUESTRA SEÑORA DE LOS REME- DIOS, TOLEDO (SIGLO XVI)
}

\author{
Laura CANABAL RODRÍGUEZ
}

Recibido: 10/09/2012

Aceptado: 04/11/2013

RESUMEN: El principal objetivo de este artículo trata de analizar a través de las Constituciones del Colegio de Doncellas de Toledo la actividad educativa femenina de la ciudad. De hecho, la importancia de promover una acción fundacional de estas características. El fundador,el arzobispo don Juan Martínez Silíceo, había realizado otras dos fundaciones con objetivos similares.

PALABRAS CLAVE: Educación femenina, Colegio de Doncellas, arzobispo Juan Martínez Silíceo, Toledo, siglo XVI.

ABSTRACT: The main objective of this article try to analyse with the Constitutions of College of Doncellas in Toledo, women's educational activity in this city. In fact., attach importance to bring an action foundational of this characteristics. The founder, archbishop Juan Martínez Silíceo, had achieved others foundations with similar objectives.

KEYWORDS: Women's education, College of Doncellas, archbishop Juan Martinez Siliceo, Toledo, sixteenth century.

A Vanessa y Jordi In Memoriam

Mujer y educación son de difícil convergencia. Afortunadamente la afinidad se produciría en el XVI. Los institutos educativos creados entonces específicamente para la formación femenina dieron un giro novedoso. Es desde ese inicio de la Edad Moderna cuando los Colegios de Doncellas comienzan una nueva senda con la función de moralizar la sociedad. Y porque solamente se iniciará el conocimiento de la instrucción, los programas educativos concretos, los resultados y sus promotores, partiendo de una primera etapa de instituciones de enseñanza que coincide con el nacimiento de aquellos centros docentes; no cabe olvidar como la Reforma y la Contrarreforma cambian los conceptos sociales y las funciones de 
cada componente de la sociedad en la Edad Moderna, la mujer recibirá en estas instituciones unos principios morales cristianos. La expansión de la cultura con el nacimiento de la imprenta durante el Renacimiento, y el reforzamiento del catolicismo con el Concilio de Trento, son algunas de las bases que conforman dicho cambio $\mathrm{y}$, es ahí donde la escolarización de la mujer supone una vía importante de control social.

A lo largo de las siguientes líneas nos acercaremos a uno de los primeros centros de enseñanza para la mujer en Castilla. El Colegio de Doncellas Nobles de Toledo fundado por uno de los arzobispos de la Sede Primada más destacados, don Juan Martínez Silíceo. Nos acercará no sólo a una sociedad en proceso de cambio, con nuevos objetivos, ahora tiene algo de cabida la mujer, nos aproxima a una ciudad de finales del siglo XVI, y por último a dos personajes muy unidos y relacionados Silíceo y Felipe II, fundador y patrón. Educación femenina, religiosidad y monarquía. Reforma y educación todo un reto en la España moderna ${ }^{1}$.

La gran labor que aparecía ante el arzobispo pone en evidencia el importante valor y afán de implicar ambos conceptos, Reforma y educación. Muy escaso es el interés despertado en los investigadores por este personaje clave en la formación del futuro Felipe II, el arzobispo de Toledo don Juan Martínez Silíceo ${ }^{2}$. La investigación se ha centrado mucho más en las otras facetas de su actividad, la enseñanza y la religiosa, en especial esta última por su relación con el establecimiento del Estatuto de Limpieza de Sangre en la catedral de Toledo. Este acontecimiento ha generado, en gran medida, un descrédito para el arzobispo desde

\footnotetext{
${ }^{1}$ Los archivos consultados: Archivo General de Palacio, (desde ahora A.G.P); Archivo General de Simancas (desde ahora A.G.S); Biblioteca Nacional de Madrid, Sección de Manuscritos (desde ahora B.N.M, Sección Mss).

${ }^{2}$ Muy limitados son los estudios que hemos localizado sobre el cardenal y arzobispo de Toledo. Con carácter general sobre los arzobispos de la ciudad Imperial, VV.AA,(1993), Los Primados de Toledo, Toledo, Junta de Castilla -La Mancha. Algo más recientes y en concreto sobre don Juan, están algunos artículos, IANNUZZI, I. (2000), «Mentalidad inquisitorial y jesuitas: el enfrentamiento entre el Cardenal Silíceo y la Compañía de Jesús», Cuadernos de Historia Moderna, 24, pp. 167-180. El más interesante sobre su persona es el R. DE ESPONA, R.J. (2005), «El Cardenal Silíceo, príncipe español de la Contrarreforma», Anales de la Fundación Francisco Elías de Tejada, 11, pp. 41-61. Algunos trabajos generales presentan unas aportaciones biográficas, así FERNÁNDEZ COLLADO, A. (1999), La Catedral de Toledo, siglo XVI: vida, arte y personas. Toledo, Diputación Provincial de Toledo, pp. 244-246. FERNÁNDEZ COLLADO, A. LOP OTÍN, Mª J. (2006) «Documentación biográfica en el Archivo Capitular de Toledo y personalidades relevantes», Memoria ecclesiae, 29, pp. 147-164. Igualmente, son relevantes los estudios dirigidos por el profesor José Martínez Millán, recordemos: MARTínEZ Millán, J. Fernández Conti, S (Coords.) (2005), La Monarquía de Felipe II: la Casa del Rey, Madrid, Fundación Mapfre- Tavera, 2 vols.
} 
nuestra perspectiva actual, lo cual ha derivado en un desinterés asumido que limita los trabajos sobre su persona y labor en una etapa muy interesante de nuestra historia. Es por ello que estas líneas y en general este estudio es un tributo no simplemente a la educación femenina, que no es poco, si no a las figuras quienes comprendiendo bien su posición y los beneficios que ello les permitía, admitieron con gran rigor y especial interés sus funciones religiosas y mucho mejor las sociales. Algo que en la actualidad se nos escapa.

\section{EDUCACIÓN FEMENINA EN SIGLO XVI . EL CASO DE TOLEDO.}

La actividad educativa de Toledo había comenzado a finales del siglo XV, entonces daría inicio el proceso de fundación del Colegio de Santa Catalina, la futura universidad, en 1.485 por bula del Papa Inocencio VIII. Pero esta institución era al igual que otras muchas de las creadas a lo largo del siglo XVI en Toledo para formar en su mayoría a los futuros miembros de la Iglesia. La oferta educativa femenina no llegará hasta la segunda mitad del siglo XVI. Será entonces cuando en Toledo, se crearan varios centros. De todos los que la ciudad albergará, el primero incluso anterior al Colegio de Doncellas, a imagen y semejanza del convento de Alcalá de Henares $^{3}$, el cardenal Francisco Jiménez de Cisneros, fundaba en Toledo el convento de terciarias regulares de San Juan de la Penitencia con su colegio femenino, en 1514. ${ }^{4}$ Desde aquel comienzo irán apareciendo Colegios si bien el segundo y más destacado será el de Doncellas Nobles del cardenal Silíceo. Desde ese momento van fundándose otros centros, el Colegio de Doncellas Jóvenes, y las

\footnotetext{
${ }^{3}$ Otros Colegios de Alcalá son analizados en algunos trabajos: AlBA AlARCos, A (1991), Doña Catalina García Fernández: fundadoras del Colegio de Doncellas Pobres de Santa Clara de Alcalá de Henares, 1633-1677, Alcalá de Henares, Institución de Estudios Complutenses. Igualmente hay en Valladolid, Fernández MARTín, L (1991), «El Colegio de Doncellas Nobles de Valladolid», Investigaciones Históricas: época Moderna y Contemporánea, 11, pp. 53-86. Para el caso de Madrid, podemos localizar el Colegio de huérfanas de Nuestra Señora de Loreto, y el de Santa Isabel de Hungría, véase en A.G.S, Gracia y Justicia, Leg.977, fols. 399 «Constituciones del Real Colego de Niñas huérfanas de Nuestra Señora de Loreto, de esta Villa y Corte de Madrid». En el mismo archivo A.G.S, Gracia y Justicia, Leg.977, fols. 399 «Constituciones del Real Colegio de Niñas huérfanas de Santa Isabel, reina de Hungría, de esa corte y villa de Madrid», Gracia y Justicia, Leg.977, fols. 399. En la Biblioteca Nacional de Madrid del Colegio de Doncellas de Salamanca, BNM, Mss, Var.28/16.

4 Sobre dicha fundación deben consultarse los estudios de Antolín Abad. ABAD PÉREZ, A (O.F.M). (1968), «San Juan de la Penitencia, obra social del Cardenal Cisneros en Toledo», Anales Toledanos, 2, pp. 1-88. Del mismo autor, «Nuevos documentos en torno a San Juan de la Penitencia de Toledo», (1976), Archivo Ibero-Americano, 36, pp. 119-123, 375-416. A.H.N, libro. 1.227 -F, fols. 57-62, «Memoria del pleito segundo entre el Colegio Mayor y el Provincial de la orden de San Francisco acerca de la extensión o conservación del Convento de monjas de San Juan de la Penitencia fundado por el Cardenal Arzobispo de Toledo en esta ciudad», en el mismo archivo A.H.N, Clero, libro 15.655. Libro de cuentas del monasterio de San Juan de la Penitencia, 1517-1545».
} 
restantes instituciones destinadas a proporcionar una dote para el matrimonio son las de fundaciones con promotores de grandes linajes, así la fundación de Doña Teresa de Haro y la de Don Alonso de Rojas, ambas para dotar a doncellas huérfanas, no propiamente colegios. Igualmente la fundación del arzobispo Fonseca para casar también a doncellas. Y uno más, dedicado a las mujeres en una situación de marginalidad, el Colegio de Nuestra Señora del Refugio patrocinada por el cardenal Gaspar de Quiroga a finales del siglo, en 1591. Por lo tanto, Colegios como tal, solo podemos decir que existieron dos, los demás son lugares de refugio y dotaciones para el matrimonio, que por otra parte también fueron necesarios en esta sociedad.

Toledo pasaba a convertirse en un foco educativo femenino con gran trascendencia donde el modelo de educación era muy similar al régimen de internado o clausura característico de la vida regular femenina y que irá lentamente instaurando en el siglo XVI. Obediencia, virtud, formación religiosa, disciplina y buenas costumbres serán las cualidades morales y la instrucción de las mujeres educadas para ser madres de familia o religiosas. Pero al menos, algo había cambiado, se buscaba una formación solo para mujeres. ${ }^{5}$

De manera contraria a lo que pudiera pensarse y sin ignorar los logros fundacionales de otros arzobispos toledanos, las fundaciones de don Juan Martínez Silíceo son destacadas dentro del ámbito educativo, especialmente en el femenino, no sólo por el Colegio de Doncellas, también por la importante función que la Casa de recogidas tendría en la ciudad. Como veremos en las siguientes páginas, la actitud del futuro cardenal al activar un espacio educativo novedoso nos permite comprender mejor la visión y la percepción de las necesidades del siglo. Merece

5 Para la etapa que analizamos aquí se ha publicado bastante en los últimos años, merece mencionarse algunos artículos, NAVA RoDRíGUEZ, T. (1991), «Especificidad y debate en torno a una historia social de la Educación», Cuadernos de Historia Moderna, 12, pp. 241-253; CAPEL MARTíneZ, R.M ( 2007), «Mujer y educación en el Antiguo Régimen», Historia, educación, 26, pp. 85-110. Para etapas posteriores, y sobre la Querella de las mujeres, son importantes los estudios, centrados en el siglo XVIII, de Franco RUBIo, G. Y no quiero dejar de citar a Isabel Morant o María del Mar Graña Cid. Considero igualmente interesante un artículo sobre la educación femenina en el siglo XVI, CANO BALLeSTA, J (1989), «Castigos y doctrinas que un sabio daba a sus hijas: un texto del siglo XV sobre educación femenina», A.I.H, Actas X , pp. 139-150. Hay que hacer hincapié en otras publicaciones WHITEHEAD, B. (ed.) (1999), Women's education in early modern Europe: a history (1500-1800), New York, Garland; VIGIL, M. (1986), La vida de las mujeres en los siglos XVI y XVII, Madrid, Siglo XXI. Esenciales son las obras: Duby, G. Y Perrot, M. (Dir.) (1992), Historia de las mujeres, Tomo I: Del Renacimiento a la Edad Moderna, Madrid, Taurus; Bonnie S. ANDERSON y Zinsser, J.P. (1992), Historia de las mujeres: una historia propia, Barcelona, Crítica, 2 vols., $2^{\text {a }}$ edición. 
que se le reconozca una nueva reflexión del sistema educativo, del objetivo y del nuevo sujeto que merece recibirla.

El Colegio de Doncellas Nobles de Toledo, se convertirá en el nuevo centro de educación de la mujer toledana, una mujer educada para la vida familiar. El nuevo objetivo, ya no es solamente las mujeres que comparten con el Señor su vida en el claustro o las pertenecientes a la nobleza, las que reciban una educación. La formación se amplía, la sociedad está nuevamente en proceso de cambios.

Hay que tener en cuenta como el patronazgo del Colegio fue inicialmente del arzobispo de Toledo para pasar tres años después a convertirse en una institución de patronazgo real bajo Felipe II, el 30 de noviembre de 1560. Y las constituciones ${ }^{6}$ que aquí analizamos son un traslado, del 17 de septiembre de 1560, de las originales otorgadas el 8 de mayo de 1557. Unos meses antes, don Juan Martínez Silíceo había formalizado la dotación de sus fundaciones: el Colegio de Doncellas, hay que recordar que el centro fue en origen fundación en 1551, el Colegio de los Infantes y , la Casa de recogidas y convento de Santa María la Blanca. Todo ello el 28 de febrero de 1557. Su testamento data del 8 de marzo de 1557 y codicilo del 21 de mayo del mismo año ambos en Toledo ante el escribano Juan Sánchez de Canales. Su deceso acaeció el 31 de mayo de 1557. El nuevo Colegio femenino será la base para las siguientes fundaciones dedicadas a la vida de la mujer, uno de los grupos marginales de la sociedad de la época.

\section{EL ARZOBISPO DON JUAN MARTÍNEZ SILÍCEO, PRECEPTOR DE FELIPE II}

Hijo de una familia humilde de Villagarcía de la Torre, en Badajoz, nacía en el año 1486, sus padres Lorenzo Martínez de Guijo y de Juana Muñoz. Latinizó su apellido de Guijo, por el de Silíceo. Realizó sus estudios en Llerena y Sevilla,

\footnotetext{
${ }^{6}$ Las Constituciones analizadas son 48 capítulos, que están en Biblioteca Nacional de Madrid B.N.M, Mss 11259/52, (Micro 14.061). También hay otras copias en el Archivo General de Palacio, Doncellas Nobles, A.G.P, P.C, D.N, Son A.G.P, P.C, D.N, Caja 91/01, es un original en pergamino de cuatro folios, fechado el 9 de mayo de 1557, en Toledo; También A.G.P, P.C, D.N, Caja 60/09 , se trata de un traslado notarial fechado el 21 de julio de 1.568 en Toledo; y otras tres copias A.G.P, P.C, D.N, Caja 91/02, en 9 de julio de 1557, en Toledo; A.G.P, P.C, D. N, Caja 91/03, en la misma fecha; y A.G.P, P.C, D.N, Caja 060/07, el 4 de julio de 1565 en Toledo, (original), traslado el 24 de junio de 1569. También se localizan en una provisión real localizada en el Archivo General de Simancas, en la sección del Registro General del Sello, A.G.S, R.G.S, X-1570. Se fecha en Madrid el 8 de octubre de dicho año. En el Archivo General de Simancas se encuentra otra fuente para el Colegio, A.G.S, Patronato Eclesiástico, $\mathrm{n}^{\circ}$ 152, «Plazos del Colegio de Nobles Doncellas de Toledo». Y merece recordarse Pedraza RuIz, E. «El Colegio de Doncellas Nobles: una institución en inminente peligro», discurso leído en la Real Academia de Bellas Artes de Toledo, el 21 de octubre de 1.984.
} 
luego en Valencia inició sus estudios con los dominicos, humanidades y filosofía. Iniciado el siglo XVI en 1507 viaja a París. Durante la estancia en Francia es muy probable que se produjera una de sus mejores etapas en su vida, su formación universitaria y su nuevo apellido e incluso la obtención de su ordenación sacerdotal. En aquél momento su protector sería el Dr. Juan de Çalada. En la Universidad de París fue alumno y profesor hasta 1516. Su primera obra se edita entonces, "Arithmética theórica et practica», de 1514. Con aquella formación en matemáticas y filosofía Silíceo regresaría a sus orígenes hispanos para impartir docencia en la Universidad de Salamanca, en la Facultad de Artes y Filosofía hacía 1516, permaneciendo en ella durante diecisiete años. Un año después entra en el Colegio de San Bartolomé, el 6 de agosto de 1517, siete años más tarde obtiene el grado de licenciado en Artes y Filosofía en 1519, licenciado en Teología en 1523 y para terminar el de maestro de Artes y Teología siendo ya catedrático. Mientras tanto sería ordenado canónigo magistral de Coria, en 1525. Llegando a convertirse en profesor de la cátedra de Filosofía Natural.

Recordemos que la universidad salmantina es uno de los centros más importantes de la Península especialmente por tratarse de un importante foco de salvaguarda de la política imperial mediante su actividad doctrinal. Además de ser el punto de referencia de la enseñanza de la denominada Segunda escolástica.

Toda su etapa de enseñanza finaliza cuando marcha a la Corte en 1534 como posible preceptor del príncipe Felipe, con siete años, a petición de la Emperatriz Isabel de Portugal. El cargo le fue finalmente encargado el 1 de julio de 1534. Al año siguiente, el 1 de enero, sería nombrado ayo de Don Felipe. Un paso trascendental tanto para el futuro rey como para el maestro y futuro arzobispo. En este último camino veamos a un Silíceo nombrado obispo de Cartagena el 23 de febrero de 1541, para alcanzar el arzobispado de Toledo el 8 de enero de 1546. Su ascenso en la vida religiosa fue en paralelo a su importancia en la vida del príncipe, pues en 1543 sería nombrado capellán mayor del futuro Felipe II.

De la inmensa labor del arzobispo resta todavía mucho por decir. Su llegada a Toledo ampliaba sus funciones en el arzobispado más importante, de manera que el establecimiento del Estatuto y su amplia capacidad de mecenazgo son los rasgos a analizar en la última etapa de su vida.

Sus implicaciones y defensa social del cristiano viejo frente a los conversos es para muchos su fracaso, mientras para otros fue su mayor logro. No hay que dejar de reconocer como la defensa del cristiano viejo había sido instituida en la sociedad bajomedieval y moderna, y como ya algunos monarcas llevaron a cabo limitaciones en las opciones sociales de los judeoconversos. Pero la importancia de 
la fijación del Estatuto de Limpieza de Sangre en la catedral, era dar un paso hacía adelante para crear un freno legal en la vida religiosa que después será esencial para alcanzar estas estipulaciones en otras sedes e instituciones, como ocurre con el cabildo de regidores de la ciudad. Es bien conocido que la primera vez que se fija en la catedral de la ciudad fue en la Capilla de Reyes Nuevos de Toledo en 1530. Pero es de interés recordar cómo esta institución forma parte de la Casa real, en su sección de Capilla. De manera, que los matices son evidentes.

Podemos buscar las raíces de su rechazo al converso o cristiano nuevo, pero dónde. La sociedad es un ambiente fértil para estos enfrentamientos y máxime en Toledo, ciudad en que desde 1449 las disputas terminaron con la quema de toda una zona de la ciudad en el denominado fuego de La Magdalena. Sin embargo, no solamente podemos incidir en las dificultades y problemática que establecía roces fáciles entre ambas partes. Fijémonos en la personalidad del por entonces arzobispo. Deberíamos retrotráenos a su estancia en la Universidad de Salamanca, su etapa de enseñanza. La difusión que hacía los años veinte del siglo tuvo la doctrina de Erasmo de Rótterdam y el examen de aquella en las conocidas como «Juntas de Valladolid», de las cuales formó parte Silíceo. Es evidente que su formación, estudio y valoración sobre ello, influiría de alguna manera o tal vez, más de lo que se valora. Él asimilaría con prontitud su concepto de defensa de la cristiandad de la cual formaba parte. Y trataría luego de hacer llegar estas intenciones y doctrinas a los Estatutos que pronto se irán poniendo en práctica. Además, no fue Toledo el primer lugar donde pretendió establecerlos. Hay que hacer hincapié en su etapa de obispo de Cartagena en 1541. Todos sus conocimientos e intentos de aplicarlo allí tuvieron su redacción y aprobación final para la catedral de Murcia el 1 de abril de 1544. El Estatuto de Limpieza de Sangre, sin embargo no se aplicaría hasta su confirmación a finales del siglo XVI. Este sería el primer intento del arzobispo por limitar y vetar en los oficios del cabildo catedralicio a los conversos quienes agrupados se enfrentaban con los cristianos viejos por el poder en los núcleos urbanos, desde finales del siglo XV.

El paso decisivo ocurrió en la Catedral Primada. La ciudad recibió a Silíceo como nuevo arzobispo el 8 de enero de 1546, al menos la toma de posesión a la que ni siquiera asistió, lo hizo en su nombre el canónigo Pedro de la Gasca. En su sede arzobispal es donde finalmente fija el Estatuto de Limpieza de Sangre que fue confirmado por el papa Paulo III, el 28 de mayo de 1548, mediante bula «Decit romanum pontificem». En defensa del Estatuto escribió una obra en la cual fundamenta la necesidad de dicha regulación, «Defensorium Statuti Toletani» es también conocida por el título «Pro estatuto ecclesiae toletanae». Descubrimos así la segura visión católica de Silíceo y su enfoque social, que no ha sido valorado bastante, su formalización de una regulación esperada por muchos y rechazada por 
otros en igual medida, es el mejor instrumento para valorar su acción política y religiosa.

Para este humilde religioso, el cardenalato llegaría el 20 de diciembre de 1555, al año siguiente el 24 de marzo de 1556, recibe el capelo cardenalicio con una fiesta en la propia catedral, un acto poco frecuente, si tenemos en cuenta que es el primer arzobispo que lo recibía en el templo.

La etapa toledana, al final de su vida, es muy fructífera para su sede, la actividad desplegada no fue simplemente el Estatuto de Limpieza de Sangre, colaboró con el rey de todas las formas que le fueron requeridas; reedificó las casas arzobispales de la sede; reconstruyó el Colegio de San Bartolomé; además de dotar a la Universidad ${ }^{7}$ de una cátedra de Filosofía. Su mecenazgo quedaba en un segundo plano ante su papel en la catedral pero esta faceta, a mi juicio, es la más importante. Su visión de las necesidades sociales en la ciudad se comprueba en sus fundaciones. De las diversas realidades, la educación y la reeducación son los dos puntos donde se centrará Silíceo. Así fundará y dotará tres centros fundamentales en la ciudad. Instituciones educativas son dos el Colegio de Doncellas y el Colegio de Nuestra Señora de los Infantes ${ }^{8}$; la tercera institución era para la reeducación femenina es la Casa de Recogidas conocida por su localización en Santa María la

${ }^{7}$ Sobre la Universidad de Toledo, en origen Colegio de Santa Catalina, hay que mencionar que fue creado por un conocido e influyente maestrescuela de la Catedral, don Francisco Álvarez de Toledo, miembro de una familia conversa, hacía 1530. De aquel personaje, cuya familia se opondría al Estatuto de limpieza de sangre en la catedral, hay algunos estudios, más numerosos son los dedicados a la Universidad. Algo menores son los dedicados a la figura del maestrescuela, pero es un personaje de gran interés. El profesor José García Oro ha publicado mucho como gran conocedor de don Francisco Jiménez de Cisneros. Sobre la obra fundacional de don Francisco Álvarez de Toledo Zapata, relacionado con el Cardenal por su cargo de maestrescuela de la catedral hay una publicación, García Oro, J (O.F.M). Portela Silva M M.J, (2003). «Santa Catalina de Toledo. Seminario y universidad de la Iglesia Primada de España», Archivo Ibero-Americano, 63, pp.405-680. He realizado algunas aportaciones, debidas en gran medida a los conocimientos que las fundaciones de vida regular me han proporcionado, pues un hermano de don Francisco es fundador de una comunidad franciscana femenina, y el propio maestrescuela su gran valedor y mecenas de aquella. CANABAl Rodríguez, L. (2006) «Don Francisco Álvarez de Toledo, maestrescuela y benefactor del convento de San Miguel de los Ángeles en Toledo», Archivo Ibero-Americano, 66, $\mathrm{n}^{\circ}$ 253-254, pp. 269-291; de la misma autora, "Conversos toledanos en un espacio de poder, la Catedral Primada. Don Francisco Álvarez de Toledo, canónigo y mecenas (ss. XV-XVI)», (en prensa). De la universidad Porres Martín-Cleto, J.(1973), Constituciones antiguas de la Universidad de Toledo, Madrid. También los estudios de Florentino Gómez Sánchez, Luis Lorente Toledo, José Carlos Gómez Menor. Canabal RodríGuez, L (2007). «Relación entre dos instituciones de Toledo: el Colegio de Santa Catalina y el convento de San Miguel de los Ángeles», Anales Toledanos, 43, pp. 47-72.

${ }^{8}$ LÓPEZ MuÑoz, J.E. El Colegio de Nuestra Señora de Infantes: un colegio para clerizones de la Catedral de Toledo (1552-1995), (Inédito). 
Blanca para recogimiento de mujeres arrepentidas. Las tres instituciones son fundadas en el mismo año de 1557, con una salvedad, el Colegio de Doncellas, que en origen ya se había fundado unos años antes en 1551, si bien las circunstancias de la edificación lo llevaron a la misma fecha de 1557.

El Colegio de los Infantes, recibía a niños entre siete y doce años, con una limitación de cuarenta miembros, los futuros mozos de coro de la catedral, denominados clerizones o «seises». Siendo el objetivo del centro la enseñanza correspondiente a sus futuras funciones en la catedral, con un cuidado programa que incluía el latín. Una formación bien diferente a la de las doncellas, con funciones y formación distinta. Los niños estarían obligados al igual que en la institución femenina a contar con limpieza de sangre, requisito que también era exigido a los profesores del centro. Situación que se había extendido por todo el Reino.

La tercera fundación es una de las menos usuales en la ciudad que a inicios del siglo XVI estaba entrando en un importante impulso social. Su objetivo estaba en parte, en la educación femenina y de otro lado, centrado en la reinserción y reeducación de las mujeres arrepentidas, es decir, las mujeres llegadas de la prostitución. Si bien en este concepto de mujer arrepentida incluía a mujeres que llevaban una vida de mendicidad y abandono. ${ }^{9}$ Nos referimos a la Casa de recogidas de Santa María la Blanca, junto a la antigua sinagoga de donde toma el nombre. Muy poco conocemos de esta fundación pero se trata de una de las más antiguas de la ciudad para mujeres necesitadas. ${ }^{10}$

Cabe señalar para concluir, que escribió abundantes obras de carácter teológico, filosófico y matemático. Entre ellas la redactada en Toledo, 1500 y 1551 « In Orationem Dominicam et saludationem Angelicam explicationes duae» obra que dedicó a Carlos V. Conocedor de las reformas religiosas del momento, conoció a Santa Teresa con la que mantuvo correspondencia, y bien sabido es su rechazo y

\footnotetext{
${ }^{9}$ Para estos temas de educación y focos sociales de pobreza, hay una obra de carácter general interesante, SANTOlaria, F. (1997), Marginación y educación. Historia de la educación social en la España moderna y contemporánea, Barcelona, Ariel. Igualmente es importante recordar otra obra de la profesora Teresa Nava, NAVA RodRíGUEZ, T. (1992), La educación en la Europa moderna, Madrid, Síntesis. Centrados en la mujer véanse: MoRANT, I. (Dir) (2005), Historia de las mujeres en España y América Latina, El mundo moderno, vol. II, Madrid, Cátedra. AmELANG .J.S, y NASH. M.J. (Coords) (1990), Historia y género:las mujeres en la Europa moderna y contemporánea, Valencia, Universidad de Valencia. WIESNER, M.E., (2000), Women and gender in early modern Europe, Cambridge, University Press. Más reciente la obra de Howe, E.T., (2008), Education and women in the early modern Hispanic World, Ashgate.

${ }^{10}$ Sobre ella esperamos poder publicar en breve un trabajo.
} 
enfrentamiento con los Jesuitas. Pero de toda su actividad creemos que podemos estar de acuerdo en varios aspectos: mantuvo siempre su compromiso con su actividad religiosa, en defensa de la Iglesia y el rey, especialmente sobre el control de la ortodoxia por la vía ofrecida por el Santo Oficio, de forma que el Estatuto de Limpieza de Sangre era para él la manera más precisa para defender el pensamiento y las ideas del Imperio católico, por excelencia. Aún así, su labor más destacada podría ser el apoyo a la educación, con especial atención a las mujeres y auxilio a los menesterosos, una parte de los grupos marginales de la sociedad toledana.

\section{CONSTITUCIONES DEL COLEGIO DE DONCELLAS}

El Colegio se fundaba el 25 de octubre de 1551, no obstante las Constituciones se fechan el 9 de mayo de 1557. Apenas unos meses antes, el 28 de febrero de 1557 , se formalizaban las dotaciones las otras dos instituciones ${ }^{11}$ y la del Colegio femenino ${ }^{12}$. Toledo contará desde ese momento con dos centros de enseñanza y un lugar de atención a las mujeres que están excluidas de la sociedad por su vida «extraviada» $\mathrm{y}$ «desordenada».

El centro educativo quedó establecido en unas casas en la parroquia de San Román, viviendas compradas a don Gómez Enríquez Manrique de Lara, y para ampliarlas las casa principales del Duque de Francavila, Don Diego Hurtado de Mendoza, en la parroquia de Santa Leocadia, pero esta ampliación se llevaría a cabo fallecido ya su fundador.

Por propio deseo del fundador el primer patrón del Colegio fue el arzobispo de Toledo, quien sería el encargado de visitarlo, y nombrar el administrador y la rectora. Hasta que la aceptación del patronazgo por parte de Felipe II, cambia esta situación. De manera que el primer administrador del Colegio fue el doctor Cristóbal Pérez nombrado por el fundador, el arzobispo Silíceo; el siguiente nombramiento será por orden real, Juan Francisco del Hoyo, fallecido este le sustituye el canónigo Hernando de Barriovero en 1576. Poco tiempo en el cargo,

${ }^{11}$ Casi finalizado el trabajo hemos localizado un artículo de gran interés GARCÍA ORO, J (O.F.M). (2002) «Educación y beneficencia en Toledo durante el reinado del Emperador», Carlos I y su tiempo: Actas del Congreso Beresit III, Toledo, Diputación Provincial de Toledo, pp. 253-288.

${ }^{12}$ En el archivo del Colegio se conserva una obra de 1.979 de gran valor por los datos que aporta, Hidalgo Lucero, L. (1979). Apuntes Históricos del Real Colegio de Nuestra Señora de los Remedios de esta ciudad de Toledo. Fundación del Eminentísimo Señor Cardenal Don Juan Martínez Siliceo, Arzobispo de Toledo, Toledo. Obra manuscrita. Anterior a esta publicación hemos localizado INFANTES, J. (1915) El Colegio de Nuestra Señora de los Remedios, vulgarmente llamado Colegio de Doncellas Nobles de Toledo, Toledo, Rodríguez y Hermano. 
pues debido a sus abusos económicos fue muy pronto retirado de él, 15 de junio de 1576, por el licenciado Francisco Rades de Andrada. ${ }^{13}$

El administrador y los restantes cargos del Colegio deberían ser de linaje y de correspondiente limpieza del mismo conforme al estatuto de la Iglesia de Toledo. Y por ello, " ni tara de judíos, moros, ni herejes..», es decir, cristiano viejo. Recordemos cómo el fundador es el cardenal que instituyó el Estatuto de Limpieza de Sangre ${ }^{14}$ en el cabildo de la catedral de Toledo en $1548 .{ }^{15}$

El arzobispo de Toledo fijaba el número de doncellas en cien, naturales de su arzobispado, de ellas seis serían parientes suyas, de su linaje, aunque fueran de otras diócesis. Con una edad de entre siete y diez años. Cuando llega el patronato real las candidatas serían divididas entre las candidatas de presentación real, sesenta y, las cuarenta candidatas restantes serían de designación arzobispal. Manteniendo para su recepción condiciones similares a las de las requeridas para los cargos que vimos antes, informaciones de sus linajes y limpieza, cristianos viejos y, eso sí, hijas legítimas, en este último caso, de no ser legítimas no entrarían en el Colegio. No obstante, dicho número se alcanzaría con posterioridad ya que al inicio de la fundación el propio arzobispo establecía que solamente se recibieran a quince doncellas, pues la renta era escasa entonces para un número tan elevado. Por lo tanto, ya hacía hincapié en la correspondencia entre renta y número de miembros del Colegio.

De todas aquellas se casarían diez cada año, de manera que si salían diez entraría otras diez nuevas; las casaderas serían por antigüedad y dote, redactada en documento público, de manera que en caso de fallecimiento sin hijos, la dote - de 100.000 maravedíes - regresaría al Colegio, excepto la tercera parte. Los

13 Sobre esta figura del arzobispado de Toledo esperamos con gran interés la obra de un compañero, Miguel Fernando Gómez Vozmediano.

${ }^{14}$ Muchas son las publicaciones centradas en los cambios generados por los estatutos de limpieza de sangre. Aquellos procesos de cambio socioreligioso se iniciaron a finales del siglo XV, si bien los problemas de los judíos son algo anteriores, mientras los conversos pasan a convertirse en un problema distinto, en parte por su acceso al poder económico y a cargos de gran trascendencia, serán los herejes del siglo XVI y XVII, los «cristianos nuevos». Recordemos algunos autores: Jaime Contreras, Teófanes Ejido, Eloy Benito Ruano, Jean Pierre Dedieu, Juan Ignacio Gutiérrez Nieto y son solo algunos. Más recientes son Stefanía Pastore, María Pilar Rábade Obradó, Juan Hernández Franco, Laura Giordano o Rica Amran.

${ }^{15}$ El cabildo catedralicio no fue el primero en incluirlo en la iglesia de Toledo. El primer Estatuto fue el de la Capilla Real de Reyes Nuevos, el 16 de octubre de 1530. Con posterioridad lo introdujo él propio cardenal en la catedral en 1548.Véase, el primero en HoROzCO, S. DE . (1981), Relaciones históricas toledanas, Toledo (introd y trans. Jack Weiner). En B.N.M, Mss. 13.038, fols. 1-164. 
candidatos a casarse con ellas serían igualmente requeridos en su linaje y limpieza de sangre para llevar a cabo un matrimonio de igual nivel social.

Había otra posibilidad dentro del Colegio, la que no quisiera casarse podría quedar en el Colegio durante toda su vida. ${ }^{16}$ La última opción que las quedaba era la de consagrarse a Dios, pero en esta elección no contarían con dote para entrar en un monasterio ya fuera de Toledo o de otro lugar. Solamente las doncellas casaderas tenían derecho a percibir una dote.

Igualmente la posibilidad de fallecimiento de alguna de ellas durante su estancia en el Colegio estaba regulado, de manera que en ese caso entraría otra en su lugar con las mismas condiciones.

Las doncellas serán sustentadas económicamente por la institución, comida, vestido dormitorio, y enseñanza. El vestido era un uniforme que constaba de un paño blanco y una insignia de Nuestra Señora.

Antes de pasar a la organización interna de la institución y a los dos elementos esenciales que fijaba la estancia de las doncellas, su educación y su vigilancia, nos centraremos en las personas que convivían con ellas y se encargaban de su mantenimiento diario.

En el Colegio la Iglesia y la capilla mayor son fundamentales para una educación cristiana y la correspondiente celebración de los oficios divinos. La asistencia religiosa estaba encargada a un capellán mayor, cuatro capellanes, dos sacristanes, sería necesaria además la presencia de algunos monaguillos. El capellán mayor y los capellanes se encargarían de confesar a las doncellas. Al tiempo que los sacristanes, sacerdotes o de orden sacro, tendrán que mantener la sacristía en buen mantenimiento, y custodiar los ornamentos. La elección de todos los mencionados era deber del administrador, de manera que al igual que se hacía con las candidatas, las informaciones serían necesarias para formar parte del Colegio. Se requerían las calidades que ya vimos de limpieza de sangre, y la pertenencia por tanto al grupo de cristianos viejos. En sus obligaciones estaba la de servir personalmente en el servicio de la Iglesia y capilla mayor del Colegio, solo en caso de enfermedad les estaba permitido su inasistencia. Si llegaban a faltar sin estar enfermos, la disciplina impuesta era la multa como ganaren. Prestemos atención a sus salarios: el capellán mayor percibía anualmente 30.000 maravedíes; el resto de capellanes bajaban en cantidad, cada uno recibía por tercios 20.000

${ }^{16}$ Incluso si prestamos atención a las constituciones serían más. 
maravedíes; y los sacristanes llegaban a cobrar por sus funciones 15.000 maravedíes anuales.

Entre sus funciones propiamente dichas, no sólo debe distinguirse, la celebración de la misa y la confesión de las doncellas, sino que la celebración de los oficios divinos estaban muy especificados incluso cuando terminaban aquellos quehaceres. Los deberes posteriores a ella, además de establecer oficios todos los sábados, se sumaban las misas cantadas. De hecho cuando finalizaba la misa el capellán mayor que la había hecho, -cada día a hora prima- y los otros cuatro capellanes - que habrían de celebrar semanalmente una misa cantada-, se reunían los cinco para «sobre el bulto que estuviere en la capilla del Colegio y canten un profundis en tono con su responso y oraciones por nuestra ánima y familia». Pero añade otras dos misas por dos de los capellanes: la primera, antes de la misa mayor; la segunda, después de dicha misa. Y al finalizar los capellanes, cada uno iría al bulto para rezar un responso por el alma del fundador y su familia. De hecho se concretan mucho los deseos del fundador por celebrar oficios y aniversarios por su alma y la del resto de la familia. Los sábados los oficios eran: la misa de Nuestra Señora cantada, por la tarde vísperas cantadas, igualmente se dirán las vísperas de la fiesta de Nuestra Señora y días de fiestas solemnes. Al día siguiente, debía celebrarse misa cantada y un sermón. $\mathrm{Y}$ es ahí donde podemos encontrar, lógicamente, un punto importante a tener en cuenta, la predicación que sería una de las bases de la educación femenina, en esta ocasión, deberían velar por el decoro cristiano de la vida de las doncellas del Colegio. De manera, que se establecían y vigilaban las conductas decorosas de las residentes en la institución. No se elegía a cualquiera para la predicación, sobre este aspecto recalca en otro capítulo, cuando afirmaba : como en los días festivos, domingos, Pascua y otras fiestas de guardar, al tiempo de la misa mayor, mientras los días de labor, más tarde, predicarían un sermón las personas elegidas por el arzobispo administrador, al terminar recibirían seis reales.

El otro lugar sagrado del Colegio, la capilla mayor sería solamente el enterramiento del arzobispo, de nadie más. Pero tardaría en llegar la fecha de dicha inhumación ya que a la muerte del arzobispo todavía no estaba finalizada la capilla mayor y don Juan Martínez Silíceo sería sepultado ${ }^{17}$ mientras tanto en Santa María la Blanca. No obstante, la capilla fue consagrada un día antes, 30 de mayo de 1557,

${ }^{17}$ Nicolau Castro, J. (1997), «El sepulcro del Cardenal Silíceo, obra de Ricardo Bellver», Goya: Revista de arte, $\mathrm{n}^{\circ}$ 259-260, pp. 407-415. 
del fallecimiento del arzobispo. La portada del Colegio es del escultor Juan Bautista Vázquez el Viejo ${ }^{18}$.

Además del administrador el Colegio contaban con la rectora, y desde el exterior llegaban el cirujano y el médico. En cuanto a su entrada en la institución, al igual que las posibles visitas, la fijación de la normativa es muy estricta. El control de las doncellas tanto interno como con el mundo exterior era bastante similar al existente en un centro de vida regular femenina. Cualquier persona, estrictamente señoras, que quisiera entrar en el Colegio estaba obligado a hacer su vista con licencia del administrador y rectora. Pero, además con un ceremonial establecido, estarían dos guardas señaladas por la rectora que «vayan y vengan a la puerta de la claustra del Colegio «una de las guardas iría tañíendo una campanilla. Este ceremonial quedaba establecido para toda persona que entrara, bien el médico, el cirujano u otra persona llegada del exterior. Y cuando las doncellas reciban en el locutorio, se aprecia la semejanza con los locutorios de los conventos o monasterios, al igual que en la clausura las doncellas estaban obligadas a contar con el correspondiente permiso de la Rectora, además durante la visita había una escuchadera y una guarda «Para que lo que hablen alli no sean» temas indecentes o livianos. La perspectiva de estricto encerramiento ${ }^{19}$ que se observa en el Colegio

${ }^{18}$ Palomero PÁramo, J. M. (1983), «Juan Bautista Vázquez el Viejo y la portada del Colegio de Doncellas Nobles de Toledo», Boletín del Seminario de Estudios de arte y Arqueología, 49, pp. 467474.

${ }^{19}$ Es más que evidente como la situación derivada de las normativas del Concilio de Trento y el conocimiento del propio arzobispo de Toledo en estos temas ha generado un estricto carácter normativo de control de las doncellas en la fundación colegial. No podemos dejar de prestar atención al Concilio que entre 1545 y 1563, centraba y regulaba todos los aspectos de la vida religiosa y las creencias del mundo católico, a cuya cabeza estaba el Imperio español. De este tema y sus aplicaciones en sínodos y concilios de las respectivas diócesis, FERNÁNDEZ Collado, A. (1.986). Concilios toledanos postridentinos: estudio y edición, Toledo, Diputación Provincial de Toledo. FERNÁNDEZ COLlado, A (1998), «Felipe II y su mentalidad reformadora en el Concilio Provincial toledano de 1565» Hispania Sacra, 50, n ${ }^{\circ} 102$, pp. 447-466. Sobre el Concilio FERNÁNDEZ Terricabras, I. (2000). Felipe II y el clero secular: la aplicación del Concilio de Trento, Madrid, Sociedad Estatal. Y para observar el paralelismo en las normativas de encerramiento, clausura estricta en el caso de las monjas, puede verse CANABAL RodRíGUEZ, L. (1998).«Felipe II y su política religiosa: el convento de San Clemente de Toledo», Felipe II (1527-1598): Europa y la Monarquía Católica, en Martínez Millán, J. (coord.). Madrid, Parteluz, vol. III, pp. 139-158. Sobre la misma comunidad toledana que hizo posible profundizar en este aspecto, gracias a documentación de gran valor para este tema CANABAL RodRÍGUEZ, L. (2003) «La aplicación de Trento en la vida regular : el convento femenino de San Clemente de Toledo», Cistercium, 232 , pp. 571-596. Vid. MARTínez RuIz, E., (dir.) (2002), El Peso de la Iglesia. Cuatro siglos de órdenes religiosas en España, Madrid, Editorial Actas. AtienZA LóPeZ, A. Iglesia Memorable. Crónicas, historias, escritos... a la mayor gloria. Siglos XVI-XVIII, Madrid, Sílex, 2012. Existen además numerosos autores cuyo interés es la vida religiosa femenina en época moderna, María Isabel Viforcos Mariñas, María Victoria López 
se extiende al cuidado de las puertas, y con ello a las llaves de las puertas de entrada guardadas por la rectora. Y se recalcaba con estas palabras «el Colegio esté muy cerrado». Asimismo ese cerramiento al mundo exterior se aprecia en la entrada de provisiones, la leña, el cartón y los restantes bastimentos entraban por la puerta que la rectora señalaba, al tener las llaves. El resto entraría por el torno. ${ }^{20}$ Pero no solamente estará presente la rectora con la correspondiente llave, estaba el administrador durante la apertura, entrada y cierre de la puerta. En ello los parecidos con los monasterios femeninos es más que notoria.

Al margen de estos condicionamientos respecto al mundo exterior y su relación con las personas llegadas desde él, las visitas. Hay que mencionar otra línea que delimitaba la llegada de las personas interesadas en formar parte del Colegio. Conforme a los estatutos existía una limitación a la entrada tanto de las doncellas como de cualquiera que ejerciera un oficio o responsabilidad, administrador, rectora, capellanes, sacristanes, etc, no serían recibidos en caso de tener una enfermedad contagiosa.

La inmensa cantidad de documentación generada en el Colegio estaría guardada en el archivo, donde habría también un libro con el currículum de las doncellas, su nombre, el de los padres, y abuelos su lugar de nacimiento, además de la fecha completa de su entrada y el nombre del arzobispo, rectora y administrador que estaba en el cargo en aquel momento. De igual manera conservaban en él las informaciones de limpieza y demás documentación de todos los restantes oficiales y empleados de la institución, incluidos otros oficiales y criados que llegaran a trabajar.

Cordón, Concha Torres Sánchez, Carmen Soriano Triguero, Karen Vilacoba Ramos, Magdalena De Pazzis Pi Corrales, Ana Sanz de Bremond y Mayáns, Francisco Javier Lorenzo Pinar además de María Leticia Sánchez Hernández, Fréderique Morant, no puedo olvidarme de Ángela Atienza, de dicha autora citada anteriormente, (2008) Tiempos de conventos. Una historia social de las fundaciones en la España Moderna, Madrid, Marcial Pons, recientemente ha publicado un trabajo sobre los conventos de la Rioja, en 2011. Para este tema en Italia, recordemos los estudios de Anne Jacobson Shutte, y las publicaciones de las norteamericanas: Sara T. Nalle, Helen Nader, Elizabeth Lehfeldt, Alison Weber, o la obra de ArEnal, E y SCHLAN, S, (1989), Untold sisters. Hispanic nuns in their own Works, Alburquerque, University of New Mexico.

${ }^{20}$ Recordar dos artículos recientes sobre la vida en el claustro en la etapa moderna, PI CORRALES, M.de P. (2010/1), «Existencia de una monjas: vivir el convento, sentir la Reforma (s. XVI-XVII)», Tiempos Modernos, 20, pp. 1-37. De un año antes, SÁnChez HernándeZ, Ma. L .(2009), «Veinticuatro horas en la vida de un monasterio de los siglos XVI y XVII», Cuadernos de Historia Moderna, 8, pp. 199-227. Cabe mencionar otro análisis más general de PosKA, A y LeHFELDT, E. (2002) «Las mujeres y la Iglesia en España en la Edad Moderna», en MeYers, D y DinAN, S. (dir.) Mujeres y religión en el viejo y nuevo mundo en la Edad Moderna, Madrid, Nancea, pp. 37-63. 
Pero ¿cómo era la vida cotidiana de aquellas doncellas?, y ¿cómo debía organizarse su educación?. Una de las partes esenciales de la educación de la mujer durante este periodo estaba fijada en la formación religiosa, y la segunda en una programación de aprendizaje muy estricta para dirigir una casa después de llegar al matrimonio. Es revelador como a través del día a día, la enseñanza y la vigilancia de la guarda tanto de las buenas costumbres, de la formación religiosa como de los conocimientos básicos para una mujer, van apreciándose en las constituciones.

Así sabemos que la actividad diaria debió de ser más completa por las tardes, después de la comida. Celebrada en el refectorio todas reunidas con la rectora, era el momento de la lectura de libros «en romance de vidas de santos y buenas doctrinas elegidas por el Arzobispo», antes de la comida todas ellas en pie y en tono bajo rezaban una bendición; y la tercera parte de esta formación durante este momento del día venía dado porque el servicio de la mesa lo hacían las doncellas para aprender «a llevar una casa». En una acción del día, tres enseñanzas. La religiosa, la de servir una casa y la educativa, lecturas de buenas doctrinas. Todo en uno. Y proseguía la formación.

Terminada la comida estaban obligadas a ir al coro juntas en procesión, cantando en un tono bajo el himno que había compuesto el arzobispo en alabanza a la Madre de Dios. Después a sus «labores y hacer lo demás que dentro del Colegio son obligadas». La última etapa de la formación eran las labores de costura en el aposento establecido para ello, y en ese momento, la lectura de vidas de santos y libros de santas doctrinas, señaladas también como antes por el arzobispo. No sabemos con detalle los quehaceres a que eran obligadas pero es razonable pensar en bordar y « otras labores que convengan saber ${ }^{21}$

Finalmente la hora de la cena era el momento en que la rectora terminado el día, en tono bajo, cantaba una oración que sigue después del himno antes mencionado.

No podemos olvidar una cuestión importante para el Colegio, la dotación tenía unos de difícil comprensión. Cómo con la mayor parte de la herencia del arzobispo se la llevaba el centro pero estuvo obligado a acatar unas condiciones. Ésta gran capacidad económica con que se dotó las imponía ciertos cumplimientos de gran

\footnotetext{
${ }^{21}$ Esta última puntualización la encontramos en una ampliación de las Constituciones del Colegio llevadas a cabo seis años después de las que hemos utilizado nosotros aquí. Son las que están en un artículo de Santolaya Heredero, L. (1994), «El Colegio de Doncellas Nobles de Toledo. Algunos puntos de sus constituciones», Espacio, tiempo y forma. Serie IV. Historia Moderna, 7, pp. 355-363. En este estudio Laura Santolaya se centra en las constituciones de 1566, en especial, recoge los puntos que están dedicados a la atención y educación de las doncellas toledanas. Desde el capítulo 29 al 81. PARro, S.R, (1857), Toledo en la mano, Toledo, tomo II, pp. 440-441.
} 
responsabilidad para un centro de estas características. A su cargo quedaban varias vinculaciones ineludibles: pagar las pensiones de los familiares del fundador, además de las raciones y quitaciones de sus sirvientes con carácter vitalicio, y por último estaban establecidos los oficiales del Colegio, es decir, el administrador era, como ya citamos, el doctor Cristóbal Pérez; el capellán mayor que fue del arzobispo, y los mayordomos Antón Rodríguez Tamayo y Yuste López de Santiago. Todos cargos vitalicios. Bien podríamos afirmar que con los bienes dotacionales que serían vendidos como era habitual, en pública almoneda, se obtendrían con ese dinero juros de renta perpetua que sería al quitar. De manera que el Colegio afrontaría con ello las obligaciones contraídas, pues las otras dos fundaciones serán mantenidas con la cantidad que se deduce del montante de las rentas del Colegio. Vemos que el Colegio de Doncellas era más que un centro de enseñanza se convertía en la base económica de las otras dos, o al menos en buena medida. ${ }^{22}$

\section{PATRONATO REAL DE FELIPE II}

Es difícil no encontrar en la ciudad de Toledo alguna comunidad de vida regular, especialmente femenina ${ }^{23}$, o un centro educativo o asistencial que no finalizara por llegar a formar parte del patronazgo de algún monarca. Sí nos fijamos en ello, los casos son frecuentes, pero no hay que poner en duda como las necesidades económicas son la base esencial de la búsqueda de protección real ${ }^{24}$ para poder hacer frente a dificultades futuras. Pero si analizamos más

22 Es un detalle importante que se puede apreciar en un documento de Simancas, A.G.S, VIII1.557. Provisión real fechada en Madrid el 4 de agosto de 1557.

${ }^{23}$ En cuanto a la vida religiosa de la ciudad, en el ámbito femenino, véanse los estudios de José Luis BARRIOS SOTOS sobre la comunidad dominicana de Santo Domingo el Real, y de este monasterio recientemente el trabajo de un compañero CAÑAS GÁlvEZ, F. (2010) Colección Diplomática de Santo Domingo el Real de Toledo: documentos reales I (1249-1473), Madrid, Sílex. Los de María Luisa PÉREZ DE TUdela sobre el monasterio de Santa Clara la Real, del padre ANTOLín ABAD (O.F.M) sobre el monasterio de terciarias franciscanas de San Juan de la Penitencia al que nos referimos en páginas anteriores, y los estudios que he ido publicando junto con CANABAL RODRíGUEZ, L (1997), Conventos femeninos de Toledo (siglos XII-XVI), Madrid, Universidad Complutense, (tesis doctoral inédita). Sin olvidar los catálogos del monasterio de San Clemente y del monasterio de Santo Domingo el Antiguo, donde se guardan varios cuadros de El Greco.

${ }^{24}$ La importancia del patronato real puede apreciarse con más frecuencia en comunidades de vida regular el ejemplo de mayor relevancia para este periodo son los monasterios femeninos de Madrid, SÁNCHEZ HERnÁNDEZ, Ma . L (1997). Patronato regio y órdenes religiosas femeninas en el Madrid de los Austrias: Descalzas reales, Encarnación y Santa Isabel, Madrid, Fundación Universitaria Española. Es interesante el trabajo de NAVA RoDRíGUEZ, T. (1999). «Mujer educada, mujer recluida: Colegios reales en la villa y corte», La creatividad femenina en el mundo Barroco hispánico, vol. 3, pp. 559-577. 
detenidamente, estos centros dependientes de la protección real la reciben no como propia fundación real, que los catalogaría como fundación directa de la monarquía; sin embargo, en el caso que nos ocupa el vínculo sería indirecto, estaríamos ante el amparo real llegado por petición personal del fundador. Ciertamente, en una pequeña parte quedarán unas cargas y responsabilidades para la monarquía, que intentará beneficiar con donaciones y apoyo las obligaciones que derivan de tal situación.

Este fue el caso del Colegio de Doncellas que poco tiempo después de ser fundado, dotado y construido solicitaba a petición de su fundador, el patronato regio a Don Felipe. El arzobispo Silíceo lo había establecido en el codicilo de su testamento y su pupilo lo aceptaría a solicitud del administrador, el doctor Cristóbal Pérez. La aceptación la llevaría a cabo el Rey el 30 de noviembre de 1560 en Toledo, siendo secretario Vázquez de Molina, junto con los licenciados: Otaloza, Mencheca, y el Doctor Velasco. Siendo registrado por el chanciller Martín de Vergara. El monarca solicitaría al Papa la confirmación y aprobación, además de ordenar la redacción de dos copias, una para el archivo de Simancas y otra para el propio Colegio.

El patronato real no terminará por ser hasta cierto punto, la salvación económica de la institución, ni tampoco cesaran los problemas. No podemos olvidar que en función de las parcelas de poder correspondientes a cada uno de los patronos, la problemática se mantendrá durante todos los siglos posteriores, pues el Rey compartía ciertos nombramientos de cargos en el centro con el arzobispo de Toledo. El arzobispo nombraría al administrador y la rectora una competencia que consta en las Constituciones, si bien las diferencias con respecto a estos términos será elemento de discusión frente al Rey que tratará de nombrar como patrono al administrador, dejando el otro cargo para el arzobispo. Problemas de dos tipologías, siendo la de carácter económico la de mejor solución al ir solventándose con algunas donaciones del Rey. ${ }^{25}$ Protección real que sería asumida por Felipe II que lo acogió bajo manto protector por el afecto que había procesado a su maestro de la infancia con quien mantuvo una estrecha relación durante su vida.

No debemos olvidar que esta fundación forma parte de las nuevas tendencias socioreligiosas y educativas características de la Contrarreforma. Es un centro de enseñanza y hasta cierto punto un centro de educación para futuras religiosas, $i$ podemos decir que se trata de un Colegio-convento?, pues no, en sentido estricto,

${ }^{25}$ A este tema y a las donaciones reales nos acercaremos en próximos estudios. 
pero sí tenía como centro de enseñanza una doble finalidad, la de educar y la de disciplinar vigilando la conducta de las mujeres del siglo.

\section{APÉNDICE DOCUMENTAL}

1560, septiembre, 7 Toledo

\section{Constituciones del Colegio de Doncellas de Nuestra Señora de los Remedios de Toledo}

B.N.M, Mss 11.259/52 (Micro 14.061)

En el nombre de Dios Padre, e hijo y spiritu santo tres personas y un solo Dios a gloria de esta santíssima Reyna de los Ángeles, santa María Madre de Dios, abogada y señora nuestra: Nos Don Juan Martínez Silíceo por la Divina miseración Cardenal de la santa Yglesia de Roma, Arzobispo de Toledo, Primado de las Españas, Chanciller mayor de Castilla, ordenamos y hacemos las constituciones, que se han de obserbar y guardar en el Colegio, que havemos dotado en esta Ciudad de Toledo en las casas, que compramos del señor Duque de Francavila , conde de Melito, al qual dicho Colegio intitulamos de Nuestra Señora de los Remedios.

Primeramente nombramos por Patrón, protector, y defendedor perpetuo del dicho Colegio de Nuestra Señora de los Remedios (fol. 2v) al Reverendissimo Arzobispo de Toledo, que por tiempo fuere, al qual rogamos y pedimos por merced quiera aceptar, y acepte el dicho Patronazgo, protección, y amparo del dicho Colegio, y de estas personas, y hacienda de él, al qual si fuere posible en cada un año, o en los tiempos como los que le parezca le visite y estando su Reverindissima persona impedida le mande visitar a persona idónea, de buena vida y costumbres, y hecha la dicha visitación assi en lo que toca a las personas del dicho Colegio como a la hacienda, y rentas de él visita por su señora mande corregir, y enmendar aquello que mas conbenga corregirse, y enmendarse, proviniendo en todo lo que mas allegado sea al servicio de Dios, bien y utilidad del dicho Colegio.

Item es nuestra voluntad, que después de los días del Administrador, y Rectora que nos nombramos para el dicho Cole (fol. 3) gio quede al dicho Reverendissimo Arzobispo, que por tiempo fuere el nombramiento de Administrador y Rectora para el dicho Colegio.

Item ordenamos, que luego que el dicho Reverendissimo Arzobispo nombrare al dicho Administrador o Rector les mande hacer información de su linaje, y limpieza conforme al estatuto, que tiene esta madre santa Yglesia de Toledo, el qual está confirmado por los summos Pontífices, para que sean limpios sin mácula, ni tara 
de judíos, moros, ni herejes, y asimismo, que la dicha información se les haga de las costumbres, honestidad y suficiencia de sus personas sobre lo qual, y sobre lo contenido en estas constituciones encargamos la consciencia al dicho Reverendissimo Arzobispo.

Item ordenamos y mandamos que esta persona, que estas informaciones fuere (fol. $3 \mathrm{v}$ ) a hacer sea christiano viejo de buena vida y costumbres, la qual se hará en esta naturaleza de los que así hubieren de ser Administrador o Rectora.

Item queremos, y mandamos, que en el dicho Colegio haya cient Doncellas todas naturales de este nuestro Arzobispado, las seis de las quales, queremos que sean deudoras nuestras, y que sean recibidas en el dicho Colegio, no obstante, que no sean naturales del dicho nuestro Arzobispado , y como estas se fueren casando, se vayan otras de nuestro linaje recibiendo, y quando alguna faltare por muerte sea luego recibida otra de manera que siempre este lleno el número de seis Doncellas de nuestro linage.

Item mandamos y ordenamos, que estas dichas Doncellas, quando fueren recibidas en el dicho Colegio sean de edad de (fol. 4) siete a diez años y no mas.

Item mandamos que el nombramiento de las dichas Doncellas, que assí se hubiera de recibir se haga de la manera, y según, que en nuestro testamento lo dejamos mandado, y sean las que se nombraren de aquella donde mas la piedad se pueda señalar, teniendo las calidades infra scriptas.

Item ordenamos, y mandamos, que antes que en el dicho Colegio sean recibidas por Comisión del dicho Arzobispo de Toledo se les vaya a hacer la información de su linage, y limpieza a los Pueblos donde fueren naturales de esta manera que se ha de hacer a los dichos Administrador y Rectora, y asimismo se les haga información de cómo son legitimos, y de legitimo matrimonio nacidas, porque no siéndolo mandamos, que no sean admitidas en el dicho Colegio. (fol. $4 \mathrm{v}$ )

Item ordenamos, y mandamos, que esta persona que fuere a hacer las dichas informaciones sea Christiano viejo y persona suficiente las quales acosta del dicho Colegio.

Item es nuestra voluntad, que al presente no sean recibidas en el dicho Colegio más número de quince Doncellas, porque de mucha parte de la renta, que hemos aplicado al dicho Colegio hauemos hecho merced a criados nuestros por todos los días de su vida, pero mandamos, y queremos que como fuere la renta, que los dichos vuestros criados llevaren vacando , vaya gozando el dicho Colegio de ella, y 
como fuere creciendo la dicha renta, assi vaya creciendo el número de las dichas Doncellas hasta que como dicho es allegue a ciento.

Item ordenamos , y mandamos, que lle (fol. 5)gada la sazón, y tiempo oportuno se casen de estas Doncellas, que assi estubieren en el dicho Colegio en cada un año diez, y como fuere cresciendo la renta del dicho Colegio, assi vayan cresciendo las dotes , que se les hubiere de dar a cada una de ellas que como dicho es en cada un año se houieren de sacar a casar, en ligar de las quales serán recibidas otras diez con las condiciones arriba dichas, de manera que no falte el número de ciento en el dicho Colegio, y que assi como fueren entrando, se vayan por su antigüedad casando de manera, que la que primero entra en el dicho Colegio preceda a la que está después.

Item ordenamos, y mandamos que las personas,que con las dichas Doncellas , se casaren se les haga información de la limpieza de su linage y costumbres por comisión del dicho Reverendissimo Arzobispo (fol. 5v) a fin de que tengan las mismas calidades y limpieza de las dichas Doncellas.

Item ordenamos, y mandamos, que los que assi se casaren con las dichas Doncellas aseguren la dote, que se les diere por instrumento público a fin de que si aconteciere morir sin hijos alguna de estas Doncellas buelba el dote al dicho Colegio , y este del asegurado excepto la tercia parte, la qual es nuestra voluntad, que pueda testar, la que assi aconteciere morir sin hijos.

Item que en muriendo alguna de estas dichas Doncellas, que el dicho Colegio estubieren entre otra en su lugar con las condiciones suso dichas.

Item ordenamos, y mandamos, que si algunas Doncellas no quisieren casar, sino que (fol 6) darse en el dicho Colegio por todos los días de su vida lo puedan hacer.

Item ordenamos, y mandamos, que si alguna de las dichas Doncellas, se quisiere meter Monja en algún monasterio de esta ciudad, o de otra parte, que no se le de ninguna dote para ello.

Item que todas las dichas Doncellas han de ser vestidas a costa del dicho Colegio y de paño blanco, y traer en el pecho la insignia de Nuestra Señora.

Item ordenamos, y mandamos que todo el servicio, que se hubiere de hacer dentro de la dicha claustra del dicho Colegio le hagan las dichas Doncellas por sus días, o semanas según que a la Rectora del dicho Colegio pareciere, a fin que quando del salieren para se casar entiendan, y sepan el servicio de sus casas. 
(fol. 6v) Iten ordenamos, y mandamos, que estas dichas Doncellas coman, y cenen juntas en el refectorio asistiendo a la Rectora.

Iten, que al tiempo del comer, y cenar o hacer colación se lean en el dicho refitorio libros de romance de vida e de santos, y buenas doctrinas los quales elegira el dicho Reverendisimo Arzobispo de Toledo .

Otrosi mandamos que sirvan a la dicha mesa las Doncellas que fueren necesarias para el dicho servicio por sus semanas.

Iten ordenamos, y mandamos, que al tiempo que estén juntas en el dicho refitorio antes de comer, o de cenar, o de hacer colación estando en pie digan todas en tono bajo la bendición siguiente.

\section{(fol.7) Bendición}

Nuestros ojos buen Dios ponemos en ti , y esperamos tu santa bendición, y que nos darás mantenimiento, pues a los brutos, animales, y aueis no lo niegas, abrid señor vuestra mano, y dadnos por quien vos sois el mandamiento de este día para que resçibido podamos mejor servir a Vuestra Muerte, damos gloria a vos Padre, E hijo y Spiritu santo agora, y para siempre jamás, y suplicamos a ilustra Divina Majestad recibais por nuestra Abogada a la Sacratisima Reyna de todo el Mundo vuestra Madre, y señora nuestra.

Iten después de hauer comido, cenado o hecho colación vayan juntas en procesión al choro, cantando entono bajo el himno por nos compuesto en alabanza de la Madre de Dios, y al fin del dirá la (fol.7v) rectora al mismo tono la oración, que se sigue después del dicho himno.

No se pone aquí el himno, ni la oración de que en el Capítulo antes de este se hace mención porque la indisposición de su señoría ilustrísima no le dio lugar para ordenarlo ni tubo tiempo.

Lo qual hecho se podían partir para sus labores, y hacer lo demás, que dentro del dicho Colegio son obligadas.

Iten ordenamos, y mandamos, que juntas todas las dichas Doncellas en el aposento a donde han de hacer sus labores haya una, que les lea libros de vidas de santos, y otros libros de santas doctrinas, quales señalare, como dicho es el dicho Arzobispo de Toledo.

Iten ordenamos, y mandamos, que quando alguna señora quisiere entrar (fol.8)en el dicho Colegio sea con licencia de la Rectora y Administrador, que por tiempo fuere, y que al tiempo de entrar, y salir vayan, y vengan hasta la puerta de 
la claustra del dicho Colegio dos guardas quales señalare la Rectora del dicho Colegio, y la una de las dichas guardas vaya tañendo una campanilla.

Iten ordenamos, y mandamos que la misma diligencia se haga con el médico, y cirujano, y con las demás personas, que necesariamente ouieren de entrar dentro de la clausura del dicho Colegio.

Iten ordenamos, y mandamos que si alguna Doncella con licencia de la Rectora del dicho Colegio, quisiere librar por el locutorio, esté con ella una escuchadera , y guarda para que oyga todo lo que en el dicho locutorio se hablare, a fin que no se tratasen cosas indecentes, ni libianas. (fol. $8 \mathrm{v}$ )

Iten ordenamos, y mandamos que el dicho Colegio este muy cerrado, y que las llaves de las puertas por donde se entrare que él las tenga la Retora del dicho Colegio.

Iten ordenamos, y mandamos, que la leña o cartón o otras prouisiones, que se metieren en el dicho Colegio sea por la puerta, que para este efecto se señalare de la qual tendrá assimisma la llave , la dicha Retora, y al tiempo del meterlas dichas provisiones estará presente el Administrador del dicho Colegio y acabadas de meterse tornara a cerrar la puerta, y hasta que sea cerrada el dicho Administrador no se quitaran de ella.

Iten ordenamos, y mandamos, que todas las demás, provisiones y otras cosas, que no fueren en, y otras cosas que no fueren en grueso se den por el torno al dicho Colegio, y no por la puerta donde se metieren los bastimentos, que fueren en mas cantidad a fin que se abra pocas (fol. 9) veces.

Iten ordenamos, y mandamos que todos los Domingos, y Pascuas, y otros días de fiestas de guardar al tiempo de la misa mayor la qual se dirá un poco mas tarde que los días de labor haya sermón, el qual pedricaran las persona, que el dicho Reverendissimo Arzobispo de Toledo nombrare, y el administrador del dicho Colegio, al qual predicador luego que haya pedricado se les darán seis reales.

Iten ordenamos, y nombramos que haya un Capellán mayor, y quatro Capellanes para que celebren el oficio Divino en la Yglesia y Capilla del dicho Colegio.

Iten ordenamos, y mandamos que cada día para siempre jamás después de esta hora de prima se digan en el dicho Colegio por el Capellán, que fuere semanero una misa cantada, la qual oficiarán los otros (fol. 9v) Capellanes. 
Otrosi queremos, y es nuestra voluntad, que acaba la misa mayor venga el Capellán, que assi lo oviere dicho, y los otros que la ouieren oficiado sobre el bulto que estubiere en la Capilla del dicho Colegio, y canten un de pro fundis en tono con su responso, y oraciones por nuestra anima, y las de nuestros Padres deudos y por las demás que en Purgatorio estubieren.

Iten ordenamos, y mandamos que se digan otras dos misas por otros dos de los dichos Capellanes la una antes de misa mayor, y las otras después, y luego como acabe cada uno de los dichos Capellanes de decir la misa venga sobre el dicho bulto y diga rezando un responso por nuestra ánima, y las demás arriba contenidas.

Iten ordenamos, y mandamos, que todos (fol. 10) los sábados se diga la misa de nuestra señora cantada, y a la tarde vísperas assimismo cantadas, y las mismas se diran las vísperas de las fiestas de nuestra señora, y de los otros días de fiestas solemnes, y el día siguiente misa cantada, y sermón.

Iten ordenamos, y mandamos, que los ornamentos, y todas las otras cosas necesarias al culto Divino están mui guardados, y mui limpios en la dicha sacristía de la dicha yglesia, los quales serán a cargo de los sacristanes de la dicha Yglesia los quales han de dar las fianzas, y seguridad necesaria para la guarda, y recaudo de los que se les encomendare.

Iten ordenamos y mandamos que los dichos sacristanes sean dos, los quales han de ser sacerdotes, o de orden sacro.

Iten ordenamos, y mandamos que asi el dicho Capellán mayor, como los Capellanes, (fol. 10 v) y sacristanes sobre dichos sean Cristianos viejos de sangre limpia, a los quales se les haga la información de su limpieza por comisión del dicho Reverendissimo Arzobispo.

Iten queremos, y mandamos, que en esta capilla del dicho Colegio no se entierre ninguna persona, porque la queremos para nos.

Iten es nuestra voluntad, y queremos que la elección del dicho Capellán mayor, y de los dichos demás capellanes, y sacristanes, y las demás personas arriba dichas, que hubieren de estar en servicio del dicho Colegio sea elección de Administrador (fol. 11), que por tiempo fuere, y los que el nombrare teniendo las calidades arriba declaradas.

Item que los dichos Capellán mayor, y Capellanes sean Confesores de las dichas doncellas. 
Item ordenamos, y mandamos que ssi el dicho Capellán mayor, como los otras Capellanes, y sacristanes residan personalmente en el servicio de la dicha Yglesia , y Capilla del dicho Colegio, y no sirban por tercera persona, sino fuere por causa de enfermedad, y si faltaren les multen como ganaren.

Iten queremos, y mandamos que al Capellán mayor se de den por sus tercios en cada un año treinta mil maravedíes, y a cada uno de los otros Capellanes veinte mil maravedíes, y a cada uno de los sacristanes quince mil maravedíes. (fol $11 \mathrm{v}$ )

Iten ordenamos, y mandamos, que haya un libro en el Archivo de el dicho Colegio donde se escriban los nombres de todas las Doncellas, y los de sus padres y abuelos, y el pueblo donde son naturales, y el día, mes, y año en que entraron en el dicho Colegio, y en tiempo de que Arzobispo, y Administrador, y Rectora.

Iten ordenamos, y mandamos que todas las informaciones, que se hicieren de la limpieza, y casta de los Administradores, Retoras, y Doncellas, y del Capellán mayor, y Capellanes, y sacristanes del dicho Colegio, y de los otros oficiales, y criados del se pongan en el archivo del dicho Colegio.

Iten ordenamos, y mandamos, que ninguno de los sobre dichos assi Doncellas como los demás sean recibidos en el dicho Colegio, si tubiere enfermedad contagiosa. (fol 12)

Iten ordenamos, y mandamos, que todos los domingos primeros del mes se lean estas nuestras constituciones estando juntas todas las personas del dicho Colegio.

Iten que podamos añadir, y quitar a estas nuestras constituciones todo lo que nos parezca; que fueron hechas en Toledo a nueve de Mayo de mil y quinientos y cincuenta y siete años.

Io Cardenalis.

Concertado con un traslado autorizado de las dichas constituciones en Toledo a siete de septiembre de mil y quinientos y sesenta años. ( fol $12 \mathrm{v}$ )

\section{La aceptación del Patronazgo del Colegio de las Doncellas.}

Don Phelipe segundo de este nombre dicho. Por quanto Don Juan Martínez Silíceo Cardenal Arzobispo de Toledo, primado de las Españas, chanciller mayor de Castilla, y nuestro maestro que fue, fundo y doto en esta ciudad de Toledo en Colegio de Doncellas intitulado Nuestra Señora de los Remedios, la qual institución, y dotación hizo con ciertas condiciones, claúsulas, y orden ansi en 
respecto de las qualidades que el administrador, rectora y Doncellas, y otros oficiales, y personas del dicho Colegio hauia de tener, como de otras cosas concernientes al dicho Colegio según que particularmente se contiene en la escritura (fol. 13) y dotación, y ordenanzas, y testamentos y otras escripturas, que cerca de esto pasaron, y el dicho Cardenal hizo a que nos referimos, y assimismo en su última voluntad, y codicilo dejo, y nombro por Patrón del dicho Colegio a Nos , y a los Reyes nuestros sucesores, y juntamente al Arzobispo, y Arzobispos, que por su tiempo fueren en esta Santa Yglesia de Toledo, dejando assi a Nos, y a los dichos Reyes nuestros successores, como a los dichos Arzobispos el nombramiento de las dichas Doncellas como en la dicha escriptura del testamento, y codicilo se contiene, a que assimismo nos referimos, e haviendonos el doctor Christóbal Pérez, Administrador del dicho Colegio, pedido y suplicado fuesemos seruidos de aceptar el dicho Patronazgo , según y como el dicho Cardenal nos lo hauía dejado suplicado . Nos mandamos a algunos del nuestro Consejo ver las dichas escripturas de dotación , institución, y testamento (fol. $13 \mathrm{v}$ ) , y codicilo , y otraer, y platicar sobre la razón que cerca del nombramiento de las Doncellas , y de los demás tocante al dicho Patrón se debía y podía tener entre Nos, y los dichos Arzobispos de Toledo, que por tiempo fueren como Patrones, que conforme a la dicha disposición juntamente con Nos, y nuestros sucessores que daban, y habiéndolo todo visto, y tratado $\mathrm{y}$, platicado con el dicho Administrador, $\mathrm{y}$ tomándose, y asentádose la orden , y forma que pareció conveniente, y consulta de nos lo, y hecho particular relación de todo teniendo consideración a que la obra e institución del dicho Colegio con las constituciones, $\mathrm{y}$ orden, $\mathrm{y}$ forma que el dicho Cardenal dejo, y ordenó es tan santa , y pía , y tan en servicio de dicho nuestro Señor, y bien y beneficio de esta ciudad, y Arzobispado, y Reyno de Toledo, y de los naturales de el, y por hauerla instituido, y hecho el dicho (fol.14) Cardenal, que como dicho es fue nuestro maestro, al qual tuvimos particular amor, y deseo de hacer nuestra merced, or favorecer, y sostener, y cuidar obra tan buena havemos acordado de aceptar como por la presente aceptamos el dicho Patronazgo por Nos, y por los Reyes de Castilla nuestros sucesores, que por tiempo fueren, y que Nos, y los dichos nuestros sucesores, como tales Patronos tomamos, y havemos, y tenemos en nuestra protección, y mano, y amparo el dicho Colegio, personas, bienes, privilegios, y excepcioes, y todo lo a él tocante, y concerniente, y les daremos, y mandaremos dar favor, y auida, y acudiremos, y favoreceremos el sostenimiento, conservación, y efecto de la dicha institución, y de lo que cerca de ello el dicho Cardenal fundador dejó ordenado, y dispuesto, y açeptamos assimismo el poder, y facultad, que nos dejó de nombrar las dichas Doncellas (fol 14 v) juntamente con los dichos Arzobispos, que por tiempo fueren, el qual nombramiento se ha de haser por la forma, y orden que se ha tratado, y asentado, combiene a saber, que de las cient Doncellas, que en el dicho Colegio ha de hauer, 
Nos y los Reyes nuestros sucessores hayamos de nombrar, y presentar las sesenta, y el dicho Arzobispo, o Arzobispos, que por tiempo fueren las otras cuarenta, guardándose siempre en quanto a las qualidades, y condiciones, que las Doncellas han de tener, lo que el dicho Cardenal dejó ordenado, y que en lugar de las Doncellas, que por Nos fueren nombradas sucediendo morir, o vacar cualquiera de ellas hayamos Nos, y nuestros sucessores de presentar otras, y lo mismo sea en las que los dichos Arzobispos presentaren, de manera, que las prebendas, y lugares que a Nos, y a los dichos Arzbispos pertenecen presentar sean asi distintas (fol. 15) y conocidas, para que sucediendo la vacante se entienda, y sepa a quien pertenece, y toca el nombramiento, y que por el presente hasta que pueda hauer el cumplimiento de las dichas cient Doncellas y en el entre tanto, que las no hubiere el nombramiento de las dichas Doncellas se haga por Nos, y los dichos Arzobispos al dicho respeto de sesenta, y quarenta, de forma que aunque sea menor el número haya la dicha diferencia, y ventaja.. Iten quanto al nombramiento de la Rectora, que en el dicho Colegio ha de hauer, y del Administrador para después de la muerte del dicho Doctor Christóbal Pérez el qual conforme a la disposición del Cardenal lo ha de ser por sus días, como quiera que en las Constituciones, que el dicho Cardenal hizo para lo tocante al Colegio, dejó declarado, que el Administrador, y Rectora fuesen nombrados por los Arzobispos, que en la dicha santa ( fol. $15 \mathrm{v}$ ) Yglesia por tiempo fuesen, pero atento quien aquello dispuso antes, que nombrase a Nos por Patrones juntamente con los dichos Arzobispos, y antes que a los dichos Arzobispos hubiese dado juntamente con Nos el nombramiento de las Doncellas, y que hauiendo después cerca de esto hecho mudanza es diferente el caso, y la razón ha sido asentada que el dicho administrador después de la muerte del dicho Doctor Christóbal Pérez sea nombrado por Nos, y por los reyes, que de Nos hubieron subcesibamente en su tiempo, y que el nombramiento de la Rectora quede a los dichos Arzobispos, y que asi en lo tocante a las dichas Doncellas, como al Administrador, y rectora se guarde y tenga la dicha orden, y forma, y con las dichas condiciones, y en la dicha forma, y manera, que lo hauemos asentado, y concertado aceptamos el dicho Patronazgo por Nos, y en nombre de los Reyes nuestros sucessores (fol. 16) en la Corona de Castilla si, y según que de suso está dicho, y declarado, y hauemos mandado, y ordenado se trahia, y haya de nuestro muy santo Padre la confirmación, y aprobación, que para el efecto de lo que dicho es sea necesario, de lo qual mandamos dar, y dimos dos Cartas de este mismo tenor firmadas de nuestra Real mano una de ellas para que se ponga en el Archivo de las nuestras escripturas Reales de Simancas, y la otra para que se ponga en el Archibo de las escripturas del dicho Colegio. Dada en la Ciudad de Toledo a treinta días del mes de Noviembre del año de mil, y quinientos, y sesenta, del nacimiento de nuestro Señor y Salvador Iesuchristo , y en el quinto año de nuestro Reynado $=$ Yo el Rey, Yo Juan Vazquéz de Molina, secretario de su Católica Majestad la fice 
escribir por su mandado $=$ el Licenciado Menchaca $=$ el Licenciado Otaloza $=($ fol. 16 v) el Doctor Velasco, registrador Martín de Vergara= Martín de Vergara por Chanciller. 